\title{
BMJ Open Systematic review and meta-analysis of diabetes mellitus, cardiovascular and respiratory condition epidemiology in sexual minority women
}

\author{
Catherine Meads, ${ }^{1}$ Adam Martin, ${ }^{2}$ Jeffrey Grierson, ${ }^{1}$ Justin Varney ${ }^{3}$
}

To cite: Meads C, Martin A, Grierson J, et al. Systematic review and meta-analysis of diabetes mellitus, cardiovascular and respiratory condition epidemiology in sexual minority women. BMJ Open 2018;8:e020776. doi:10.1136/ bmjopen-2017-020776

- Prepublication history and additional material for this paper are available online. To view these files, please visit the journal online (http://dx.doi org/10.1136/bmjopen-2017020776).

Received 22 November 2017 Revised 8 March 2018 Accepted 15 March 2018

\section{Check for updates}

${ }^{1}$ Faculty of Health, Social Care and Education, Anglia Ruskin University, Cambridge, UK ${ }^{2}$ Academic Unit of Health Economics, Leeds Institute of Health Sciences, University of Leeds, Leeds, UK

${ }^{3}$ Public Health England, London, UK

Correspondence to Professor Catherine Meads; Catherine.Meads@anglia.ac.uk

\section{ABSTRACT}

Objective Sexual minority women (SMW) experience higher chronic disease risk factors than heterosexual counterparts. However, it was unclear if these risks translate into higher physical condition rates. This systematic review evaluates cardiovascular disease (CVD), hypertension, respiratory disease and diabetes mellitus in SMW.

Methods A protocol was registered with the Prospero database (CRD42016050299). Included were studies reporting mortality, incidence or prevalence of the abovelisted conditions in SMW compared with heterosexual women. Databases (platforms) searched from 2010 to December 2016 were Medline (Ovid), Embase (Elsevier), Cumulative Index to Nursing and Allied Health Literature (Elsevier), PsycINFO (Ovid), Social Policy and Practice (Ovid), Cochrane CENTRAL (Cochrane Library), Science Citation Index (Web of Science), and CAB Abstracts (Ovid). Search terms included Medical Subject Heading (MeSH) terms and text words. Extensive additional searches were conducted in specialist academic journals and websites. Two reviewers checked study eligibility. One independently extracted data and assessed quality, checked by a second reviewer, with disagreements resolved through discussion. The Critical Appraisal Skills Programme cohort checklist was used to assess risk of bias. Meta-analysis was conducted where more than four studies reported the same outcomes, with Comprehensive Meta-Analysis software, using adjusted ORs (AORs) and random-effects models. Heterogeneity was assessed using $\mathrm{I}^{2}$ test.

Results Identified were 23103 citations, 692 full texts screened and 16 studies included (in 18 papers). One reported mortality (from Denmark), none incidence and 15 prevalence (14 USA, 1 Australia). Same-sex cohabiting women had higher mortality rates compared with opposite-sex cohabiting women in CVD ( $\mathrm{HR}=1.37$ (95\% $\mathrm{Cl} 1.22$ to 1.54)) and respiratory disease ( $\mathrm{HR}=2.10(95 \%$ $\mathrm{Cl} 1.74$ to 2.53)). AOR meta-analyses of seven studies showed higher asthma rates in lesbians $(\mathrm{OR}=1.44(95 \%$ $\mathrm{Cl} 1.27$ to 1.64$\left.), \mathrm{I}^{2}=0 \%\right)$ and bisexual women ( $\mathrm{OR}=1.64$ (95\% Cl 1.41 to 1.89 ), $I^{2}=0 \%$ ) but no differences for CVD (5 studies), hypertension (5 studies) or diabetes mellitus (7 studies)

Conclusions These new health estimates require further confirmatory epidemiological studies, and investigation into potential environmental, hormonal, physiological, psychological or genetic causes. This would be supported
Strengths and limitations of this study

- A major strength is that this is the first numerical estimate of the relative prevalence of diabetes mellitus, cardiovascular and respiratory diseases in lesbians and bisexual women.

- We used extensive searches from a number of different sources, not just electronic databases and reference lists but also specialist academic journals and websites, to ensure we found all relevant studies.

- We used a wide definition of sexual minority women (SMW) to include identity, behaviour and partnership to be able to include all SMW irrespective of being sexually active or in a partnership. This will widen the generalisability of the systematic review.

- Considerable efforts were made to avoid double-counting of participants from different studies when entering data, but some double-counting may have occurred due to the nature of the surveys used in the studies.

- We used adjusted ORs to meta-analyse, which means that the results were more comparable than using unadjusted prevalence estimates. However, none of the adjusted ORs were adjusted for smoking status, which is a limitation of the included studies.

by routine collection of sexual identity measures in population-level epidemiological surveys.

\section{BACKGROUND}

Sexual minority women (SMW) include lesbians, bisexual women, women who have sex with women, women who have sex with men and women, and women who are married to or cohabit with another woman in a committed relationship. Public Health England estimates that at least $2.5 \%$ of the population identify as lesbian, gay or bisexual. ${ }^{1}$

Chronic disease risk factors include poor diet, lack of exercise, obesity, smoking, excessive alcohol intake, anxiety, depression, hypertension and high cholesterol levels. ${ }^{2-4}$ In 
general, SMW populations experience disproportionate behavioural risks to health and higher chronic disease risk factors than their heterosexual counterparts. ${ }^{56}$ Due to a lack of research so $\mathrm{far}^{6}{ }^{6}$ it is unclear whether these risk factors translate into higher rates of physical health conditions.

Past research has highlighted some aspects of health inequalities experienced by SMW but also identified significant and persistent gaps in the evidence, ${ }^{5}$ 7-10 including in relation to common physical conditions such as cardiovascular disease (CVD), respiratory tract disease and diabetes mellitus. These are some of the leading causes of death and disability for women, ${ }^{11}$ and up to now there have been no published summary estimates of the relative prevalence of these conditions in SMW compared with heterosexual women.

There have been two recent systematic reviews of physical health in SMW. ${ }^{12}{ }^{13}$ Eliason $^{12}$ reviewed evidence on prevalence and risk of a variety of conditions, and Simoni et $\mathrm{al}^{13}$ investigated disparities in physical health conditions in SMW. Since these systematic reviews were conducted, more prevalence studies have been published. This systematic review includes all relevant recent evidence (published from 2010 onwards) on the mortality, incidence and prevalence of specific physical health conditions of CVD, hypertension, respiratory disease and diabetes mellitus in SMW compared with heterosexual women, and conducts meta-analyses in order to derive up-to-date prevalence estimates of these conditions and determine whether there are different rates in SMW compared with heterosexual women.

\section{METHODS}

A protocol was registered with the Prospero database (CRD42016050299) for research investigating all aspects of health and experience of healthcare in SMW, of which this project is part. Patients and the public were not involved with the design or conduct of this systematic review. The inclusion criteria for this systematic review were any published comparative studies in any language, published from 2010 onwards, comparing specific rates (see below) in SMW (any definition including identity, behaviour or cohabitation status) of any age compared with heterosexual women (any definition including identity, behaviour or cohabitation status) of any age in any country or setting. The following self-report or objectively measured rates were included: mortality, incidence and prevalence of CVD, hypertension, diabetes mellitus (any type), and respiratory diseases including asthma.

\section{Searches}

Database searches were conducted in two phases. First, searches were conducted by Public Health England Knowledge and Library Service in May 2015. Second, searches were conducted by the first author (CM) in December 2016, with dates from January 2015 to December 2016. Databases (platforms) searched were Medline (Ovid),
Embase (Elsevier), Cumulative Index to Nursing and Allied Health Literature (Elsevier), PsycINFO (Ovid), Social Policy and Practice (Ovid), Cochrane CENTRAL (Cochrane Library), Science Citation Index (Web of Science), and CAB Abstracts (Ovid). EPPI-Reviewer V.4, EndNote and Microsoft Excel were used to sift citations. Search terms included Medical Subject Heading (MeSH) terms and text words for sexual minority (eg, lesbian, bisexual, homosexual, WSW, WSMW, same sex). We then searched a large number of full texts for the physical conditions listed above. Searches were not limited to the English language. Examples of search strategies for four databases from the December 2016 searches are shown as online supplementary data.

In addition to database searches, reviews and summaries of lesbian, gay, bisexual and transgender (LGB\&T) health were examined for relevant evidence. $L G B \mathcal{E} T$ T Health Research Journal (all issues), Journal of Lesbian Studies (2014-2016) and Journal of Gay E Lesbian Mental Health (2014-2016) were searched. Previous projects by the first author (CM) were searched for relevant evidence and, from a previous project, a list of currently active researchers in LGBT health with their publications were reviewed. Web pages of several researchers known to be active in SMW research were searched. The UK National LGB\&T Partnership monthly newsletter from February to October 2016 was sifted for relevant up-to-date work that had not yet been published. UK national survey websites were also sifted for information on sexual identity and health (Integrated Household Survey, Scottish Health Survey, Welsh Health Survey and Health Survey for England).

\section{Study selection, data extraction, quality assessment and synthesis}

Full-text copies of references matching inclusion criteria were obtained. Two reviewers (CM and AM) checked study eligibility. One independently extracted data from studies into the report (CM) and these were checked by another reviewer (JG), with disagreements resolved through discussion. Characteristics and results of all included studies were described through narrative synthesis. Tabulation was used where there was more than one study reporting the same outcome. Where there was overlap in study populations, the largest included population was used where outcomes of interest were reported. The Critical Appraisal Skills Programme checklist for cohort studies was used to assess quality for all studies. Since there is no established and validated quality checklist specifically for cross-sectional surveys, using the same checklist for all provided consistency in quality assessment across studies. Meta-analysis was conducted where there were four or more discrete studies reporting the same outcome. This included both unadjusted prevalence estimates (with Review Manager V.5.3 software) and adjusted ORs (AORs) using inverse variance (with Comprehensive Meta-analysis V.3). Random-effects models were used for both. Statistical heterogeneity was assessed using the $\mathrm{I}^{2}$ 
test, using standard thresholds for high, medium and low heterogeneity. ${ }^{14}$ There were insufficient studies reporting the same outcomes to be able to construct a meaningful funnel plot to assess publication bias.

\section{RESULTS}

\section{Description of studies}

A total of 23103 citations were identified, 22763 from the first searches and 340 from the second searches (see online supplementary appendix figure 1). Full texts of 692 papers were screened for potential relevance. Sixteen studies were included, ${ }^{15-30}$ described in 18 papers-the study by Clark $e t a l^{31}$ contained a subset of the participants in the study by Everett $e t a l,{ }^{20}$ and the study by Wallace $e t$ $a l^{32}$ contained a subset of those in the study by Boehmer et al. ${ }^{17}$ For the characteristics of the included studies see table 1, and for participant baseline characteristics see online supplementary appendix table 1 .

One study examined mortality rates; Frisch and Simonsen ${ }^{24}$ reported HRs for mortality by sexual orientation in a large national cohort from Denmark by various causes of death ( $\mathrm{n}=6.5$ million, approximately $50 \%$ women).

No studies investigated incidence, and 15 studies investigated prevalence. ${ }^{13-23}$ 25-30 Two were based on single waves of cohort studies (Everett and Mollborn, ${ }^{20}$ also reported in Clark et $a l^{31}$ and McNair and Hegarty ${ }^{29}$ ). The first ${ }^{20}$ was based in the USA and used wave IV data from the National Longitudinal Study of Adolescent Health. The second ${ }^{29}$ used 1-year data from an Australian study of young women aged 18-23 selected at random from the Australian Medicare database. The remaining 13 studies were from the USA and used one or more year's data from repeated cross-sectional surveys. Eight of these used Behavioral Risk Factor Surveillance System (BRFSS) surveys, either using a national sample from different years ${ }^{1516}$ or for specific states (Massachusetts, ${ }^{18}$ Oregon, ${ }^{25}$ North Carolina ${ }^{28}$ and Washington State ${ }^{1922} 23$ ). Other surveys used included the National Health Interview Survey, ${ }^{26}{ }^{30}$ the California Health Interview Survey, ${ }^{17}{ }^{32}$ the Youth Risk Behavior Surveillance System ${ }^{27}$ and the National Health and Nutrition Examination Survey. ${ }^{21}$

One group of studies ${ }^{19223}$ reported different outcomes for different subsets (such as age ranges) of the same repeated survey for different years. Ward $e t a l^{30}$ investigated a subset of the population in Jackson $e t$ al, ${ }^{26}$ but Ward $e t a l^{30}$ reported asthma whereas Jackson $e t a l^{26}$ did not, so both papers for this study have been included. Wallace $e t a b^{32}$ used a subset of the sample in Boehmer et $a l^{17}$ and reported the same outcomes, so these results are not reported here. Everett and Mollborn ${ }^{20}$ and Clark et $a l^{31}$ reported different outcomes from the same population, so both papers for this study have been included.

Quality assessment found similar quality issues across studies and are reported in online supplementary appendix table 2 . The cohort studies ${ }^{20}{ }^{29}$ reported results as if they were cross-sectional surveys by not using follow-up data. The main quality issues were that health conditions were ascertained mostly by health self-report; the main exception was in Everett and Mollborn (and Clark et al), ${ }^{20} 31$ where interviewers measured blood pressure. Also, weighted prevalence percentages were reported in several included studies (see online supplementary appendix table 1), but the weighting factors used were often unclear.

\section{Main findings}

For CVD mortality and for respiratory tract disease mortality, Frisch and Simondsen ${ }^{24}$ found that same-sex cohabiting women had higher mortality rates than opposite-sex cohabiting women for these diseases (HR 1.37 (95\% CI 1.22 to 1.54 ) and HR 2.10 (95\% CI 1.74 to 2.53), respectively), but that same-sex married women had similar mortality rates to opposite-sex married women (HR 1.32 (95\% CI 0.75 to 2.33) and HR 0.85 (95\% CI 0.36 to 2.05 ), respectively). The sample sizes were larger for same-sex cohabiting women $(n=207$ and $n=111)$ than same-sex married women ( $\mathrm{n}=12$ and $\mathrm{n}=5)$, and no conclusions can be drawn from the same-sex married women data as sample sizes were too small.

The numerical prevalence results are presented in table 2 (asthma), online supplementary appendix table 3 (CVD), online supplementary appendix table 4 (hypertension) and online supplementary appendix table 5 (diabetes mellitus). They demonstrate that the way these rates were reported varied across the studies; for example, some studies presented results for SMW compared with heterosexual women, whereas others presented results separately for lesbians and for bisexual women. Percentages of women with conditions varied across the studies, most notably hypertension which varied from $14.7 \%{ }^{21}$ to $65.3 \%{ }^{17}$ in heterosexual women. Most studies presented AORs, as well as the adjusted or unadjusted percentages, but fewer gave measures of spread such as $95 \%$ CIs or SEs. One study ${ }^{26}$ presented results for heart disease and stroke separately and found no difference in rates between any of the groups (see online supplementary appendix table $3)$. One study ${ }^{30}$ presented results for chronic obstructive pulmonary disease, which found higher rates in bisexual women compared with heterosexual women but not for lesbians (prevalence in lesbians 6.0\% (95\% CI 3.2 to 11.0 ), bisexual women $13.6 \%$ (95\% CI 6.9 to 25.2 ), heterosexual women $6.4 \%$ ( $95 \%$ CI 5.9 to 6.8 )).

\section{Meta-analysis}

There were sufficient studies (ie, $\mathrm{n}>4$ ) presenting results for CVD, hypertension, asthma and diabetes (any type) in lesbians and in bisexual women for meta-analyses to be conducted.

Meta-analyses of unadjusted prevalence (see figure 1, online supplementary appendix figures $2 \mathrm{a}, \mathrm{b}, 3 \mathrm{a}, \mathrm{b}$, and $4 a, b)$ showed no difference in CVD (lesbian $\mathrm{OR}=0.94$ (95\% CI 0.73 to 1.21 ) and bisexual women $\mathrm{OR}=0.90$ (95\% CI 0.54 to 1.51$)$ ) but lower prevalence of hypertension (lesbian OR=0.82 (95\% CI 0.72 to 0.94 ) and bisexual 


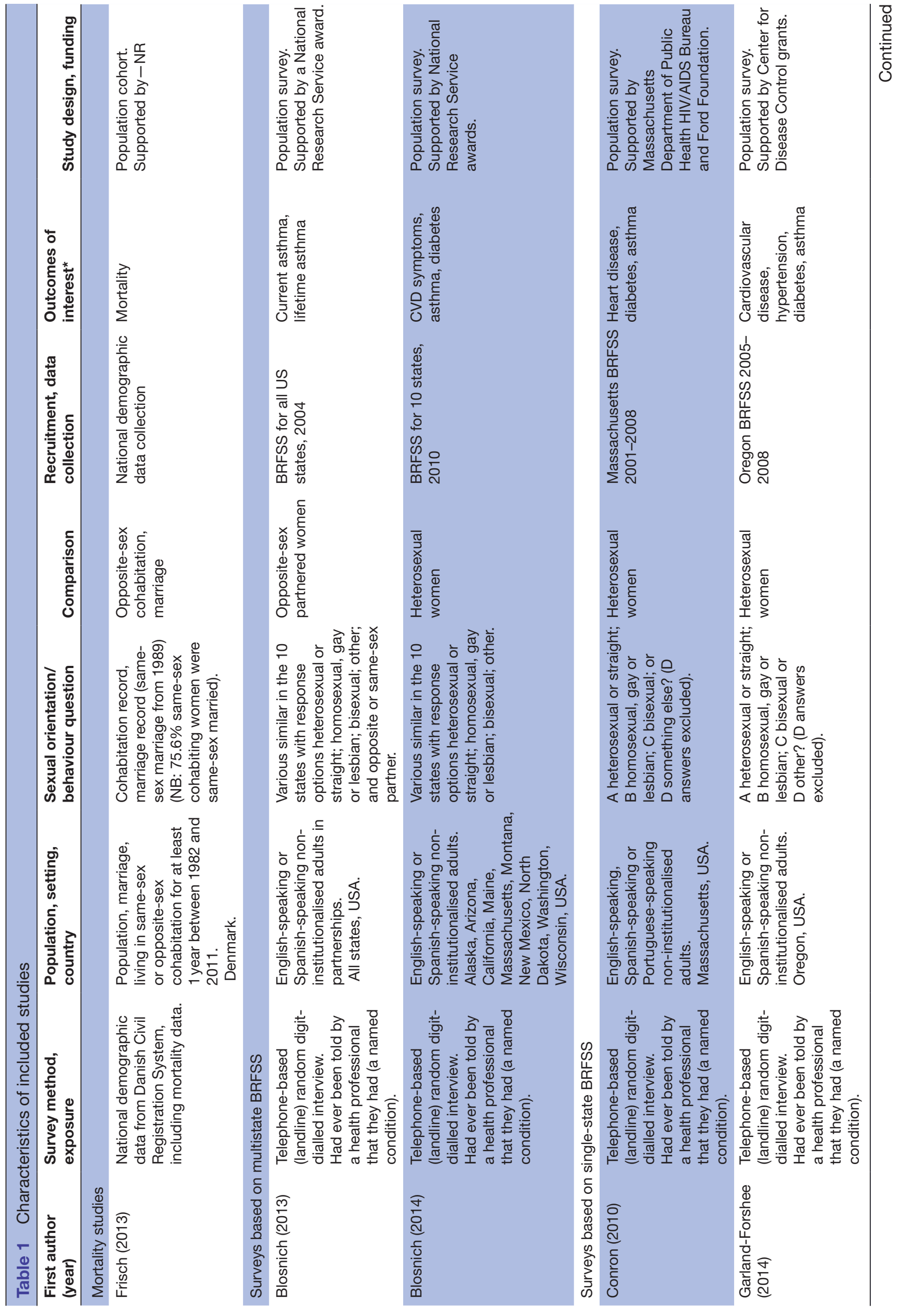

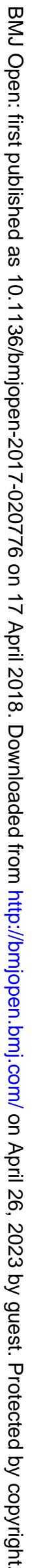




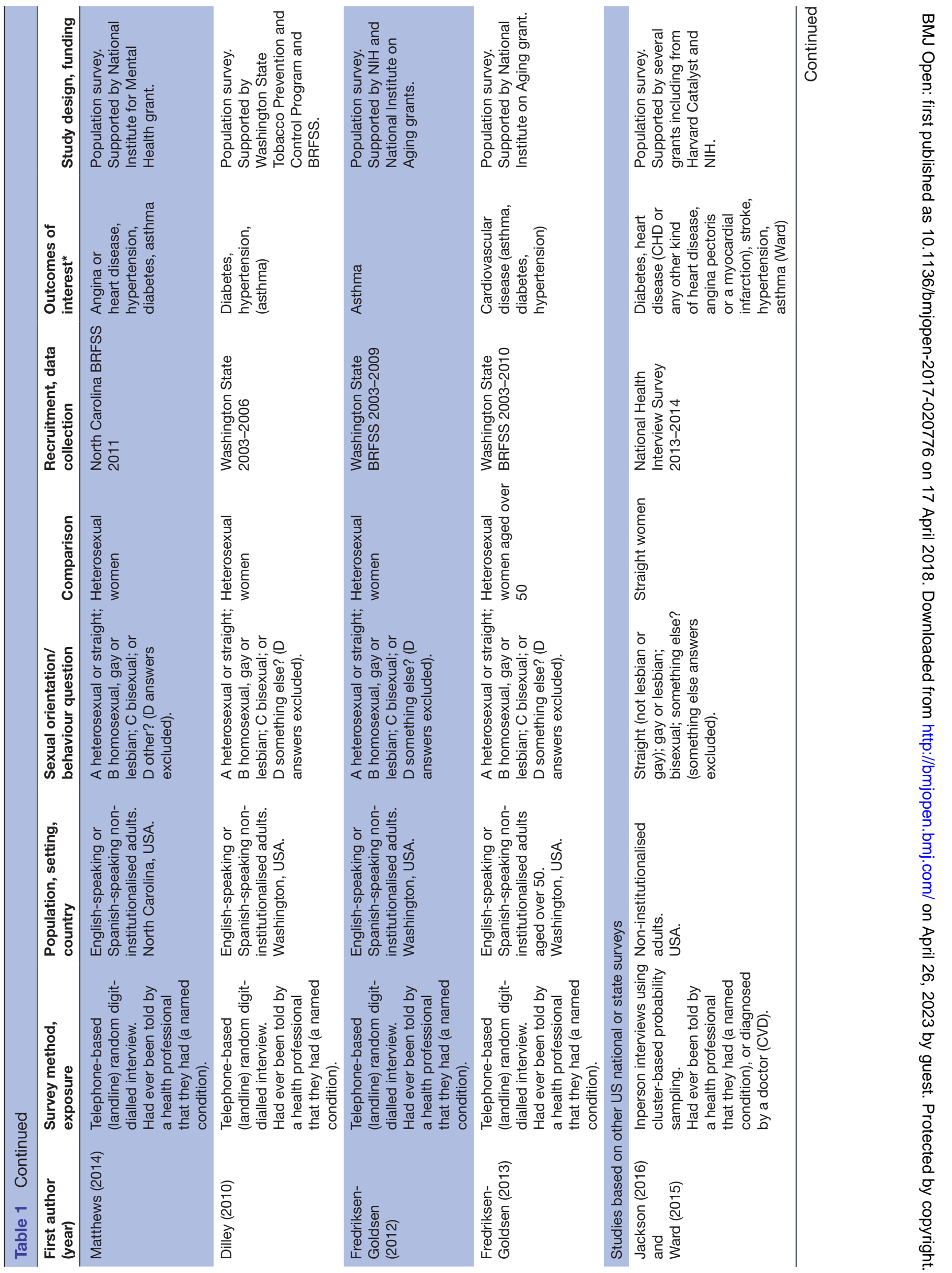




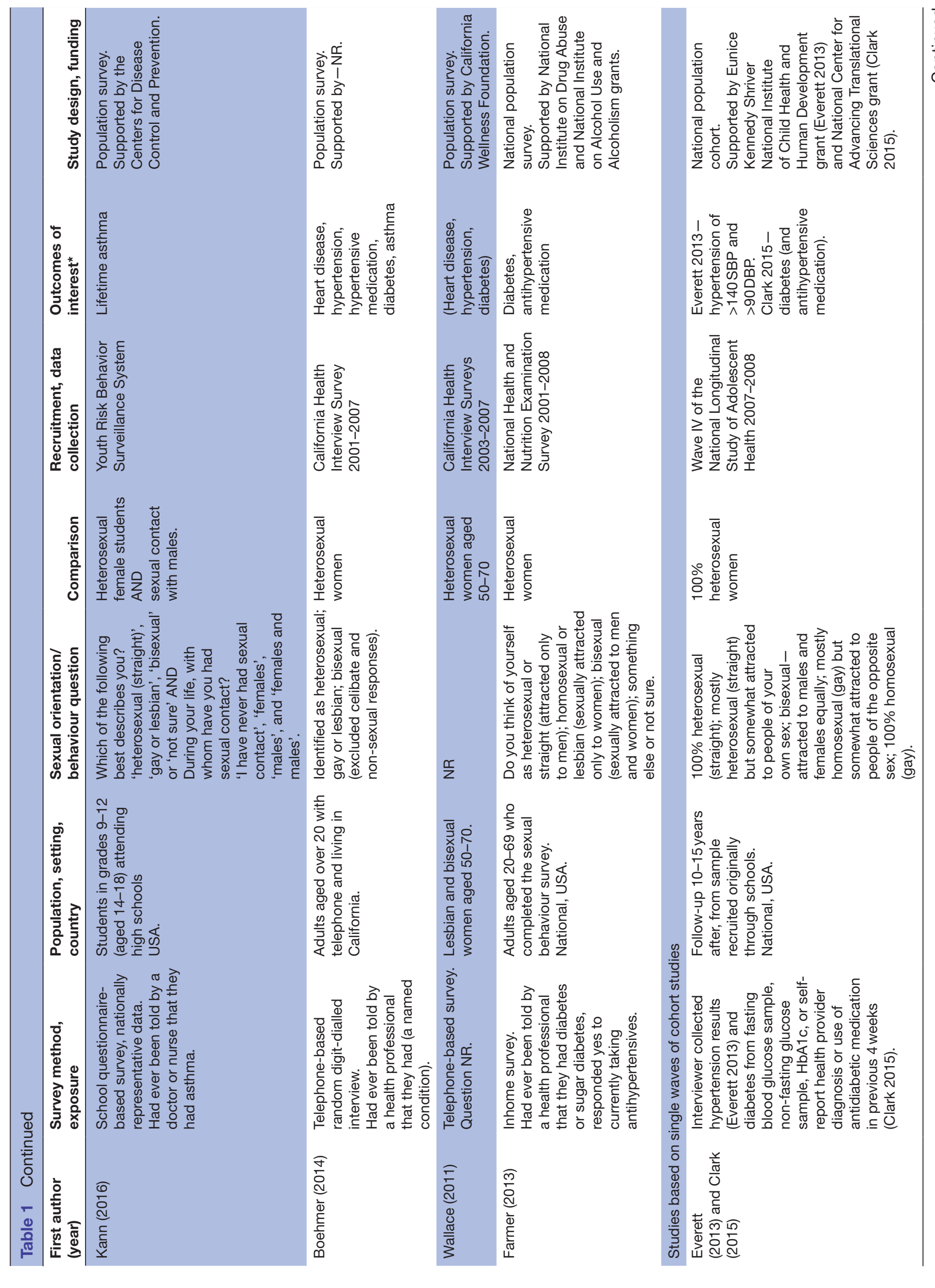


women OR=0.64 (95\% CI 0.49 to 0.85$)$ ). There was higher prevalence of asthma (lesbians OR=1.47 (95\% CI 1.32 to 1.63 ) and bisexual women $\mathrm{OR}=1.97$ (95\% CI 1.71 to 2.26), and combined for all SMW OR=1.68 (95\% CI 1.52 to 1.85$)$ ). For diabetes mellitus there was no difference in prevalence between lesbians and heterosexual women but lower prevalence in bisexual women $(\mathrm{OR}=0.86(95 \%$ CI 0.65 to 1.12 ) and $\mathrm{OR}=0.70$ (95\% CI 0.54 to 0.91$)$ ).

Meta-analyses of adjusted ORs (all adjusted for age) showed increased rates of asthma in lesbians and in bisexual women compared with heterosexual women (ORs $=1.44$ (95\% CI 1.27 to 1.64$), \mathrm{I}^{2}=0 \%$; and $1.64(95 \%$ CI 1.41 to 1.89$), \mathrm{I}^{2}=0 \%$ ). They showed no differences for lesbians or bisexual women compared with heterosexual women for CVD (ORs=1.34 (95\% CI 0.97 to 1.85$)$, $\mathrm{I}^{2}=45 \%$; and 1.08 (95\% CI 0.80 to 1.47 ), $\mathrm{I}^{2}=0 \%$ ), for hypertension (ORs $=0.98$ (95\% CI 0.86 to 1.14$), \mathrm{I}^{2}=0 \%$; and 1.08 (95\% CI 0.86 to 1.35$\left.), \mathrm{I}^{2}=39 \%\right)$ and for diabetes mellitus (ORs=1.11 (95\% CI 0.91 to 1.36$), \mathrm{I}^{2}=0 \%$; and $1.01(95 \%$ CI 0.75 to 1.36$), \mathrm{I}^{2}=51 \%$ ).

\section{DISCUSSION \\ Summary of main findings}

Results from a single large study reporting mortality rates $^{24}$ showed that there was no difference in cardiovascular or respiratory tract disease mortality rates in same-sex married compared with opposite-sex married women, but higher mortality rates in same-sex cohabiting women compared with opposite-sex cohabiting women.

Meta-analyses of adjusted ORs of disease prevalence showed no differences in CVD, hypertension or diabetes mellitus prevalence, but a higher prevalence of asthma in SMW compared with heterosexual women.

\section{Discussion of main findings}

A key finding was the higher prevalence, from the adjusted OR meta-analysis, of asthma in lesbians and bisexual women. Asthma is caused by a mixture of genetic and environmental factors. Higher rates are associated with anxiety, but it is not known if asthma causes psychological problems or if psychological problems lead to asthma. ${ }^{33}$ Nevertheless, studies have shown higher rates of mental health problems including anxiety in SMW. ${ }^{34}{ }^{35}$ Asthma is also more common among those who are economically disadvantaged, and a consistent finding in studies included in the systematic review was that SMW had below-average incomes. ${ }^{15-1721} 29$ Asthma is also more common among current or former smokers. Several included studies showed higher rates of smoking or tobacco use among SMW. ${ }^{15} 16$ 19-21 23252628 However, only one of the studies reporting asthma prevalence clearly controlled for smoking behaviour. ${ }^{15}$

The finding of lower hypertension prevalence and no difference in the adjusted OR meta-analysis in lesbians and bisexual women was unexpected. Higher rates of hypertension are associated with lack of exercise and obesity. Several of the included studies demonstrated 


\begin{tabular}{|c|c|c|c|c|c|c|c|}
\hline Study name & Heterosexual & Lesbian & AOR $(95 \% \mathrm{Cl})$ & Bisexual & AOR $(95 \% \mathrm{Cl})$ & SMW & AOR $(95 \% \mathrm{Cl})$ \\
\hline Blosnich $(2014)^{\star}$ & $\begin{array}{l}15.3 \% \dagger(\mathrm{SE} \\
0.003)\end{array}$ & $\begin{array}{l}22.2 \% \dagger \\
\text { (SE 0.03) }\end{array}$ & $\begin{array}{l}1.50 \\
(1.04 \text { to } 2.16) \ddagger\end{array}$ & $\begin{array}{l}26.4 \% \dagger \\
\text { (SE 0.04) }\end{array}$ & $\begin{array}{l}1.68 \\
\text { (1.07 to } 2.63) \ddagger\end{array}$ & & \\
\hline $\begin{array}{l}\text { Blosnich (2013) } \\
\text { (lifetime diagnosis) }\end{array}$ & $14.6 \% †(N R)$ & & & & & $26.1 \% †(N R)$ & $\begin{array}{l}1.72 \\
\text { (1.11 to } 2.65) \ddagger\end{array}$ \\
\hline $\begin{array}{l}\text { Blosnich (2013) } \\
\text { (current diagnosis) }\end{array}$ & $9.5 \%$ (NR) & & & & & $21.4 \%$ (NR) & $\begin{array}{l}2.09 \\
\text { (1.30 to } 3.36) \neq\end{array}$ \\
\hline Boehmer (2014)§ & $13.7 \%$ (SE 0.16) & $\begin{array}{l}20.8 \% \\
\text { (SE } 1.70)\end{array}$ & $\begin{array}{l}1.41 \\
\text { (1.14 to } 1.73) \ddagger\end{array}$ & $\begin{array}{l}21.5 \% \\
\text { (SE 1.76) }\end{array}$ & $\begin{array}{l}1.52 \\
\text { (1.24 to } 1.87) \ddagger\end{array}$ & NR & NR \\
\hline Conron $(2010)^{*}$ & $17.4 \% \dagger($ SE 0.3) & $\begin{array}{l}24.9 \% \dagger \\
\text { (SE 2.3) }\end{array}$ & $\begin{array}{l}1.68 \\
\text { (1.32 to } 2.14)\end{array}$ & $\begin{array}{l}25.7 \% \dagger \\
\text { (SE 3.1) }\end{array}$ & $\begin{array}{l}1.58 \\
\text { (1.15 to } 2.18)\end{array}$ & NR & NR \\
\hline $\begin{array}{l}\text { Fredriksen-Goldsen } \\
(2012)^{\star}\end{array}$ & $16.5 \% \dagger$ & $19.9 \% \dagger$ & $1.23(\mathrm{NR})$ & $31.9 \% \dagger$ & 2.17 (NR)‡ & NR & NR \\
\hline $\begin{array}{l}\text { Garland-Forshee } \\
(2014)^{*}\end{array}$ & $\begin{array}{l}12.1 \% \dagger \\
\text { (11.5 to } 12.7)\end{array}$ & $\begin{array}{l}15.4 \% \dagger \\
\text { (10.8 to } 21.7 \text { ) }\end{array}$ & $\begin{array}{l}1.2 \\
(0.8 \text { to } 1.9)\end{array}$ & $\begin{array}{l}25.6 \% \dagger \\
\text { (18.6 to } 34.2 \text { ) }\end{array}$ & $\begin{array}{l}2.4 \\
\text { (1.5 to } 3.6) \ddagger\end{array}$ & NR & NR \\
\hline $\begin{array}{l}\text { Kann (2016) by } \\
\text { sexual identity }\end{array}$ & $\begin{array}{l}23.0 \% \dagger \\
\text { (21.1 to } 24.9 \text { ) }\end{array}$ & NR & NR & NR & NR & $\begin{array}{l}28.3 \% \dagger \\
\text { (24.4 to } 32.6)\end{array}$ & NR \\
\hline $\begin{array}{l}\text { Kann (2016) by } \\
\text { sexual behaviour }\end{array}$ & $\begin{array}{l}25.8 \% \dagger \\
\text { (23.5 to 28.2) }\end{array}$ & NR & NR & NR & NR & $\begin{array}{l}31.4 \% \dagger \\
\text { (26.9 to } 36.4 \text { ) }\end{array}$ & NR \\
\hline Matthews (2014) & $15.7 \% \dagger$ & NR & NR & NR & NR & $27.7 \% \dagger$ & $\begin{array}{l}1.94 \\
\text { (0.96 to } 3.92)\end{array}$ \\
\hline McNair (2011)§ & $9.4 \%$ & $10.4 \%$ & NR & $18.0 \% \ddagger$ & NR & NR & NR \\
\hline $\begin{array}{l}\text { Ward (2015) (current } \\
\text { diagnosis) }\end{array}$ & $\begin{array}{l}8.5 \% \\
(7.9 \text { to } 9.0)\end{array}$ & $\begin{array}{l}9.5 \% \\
(6.2 \text { to } 14.4)\end{array}$ & $\begin{array}{l}1.11 \\
(0.70 \text { to } 1.76)\end{array}$ & $\begin{array}{l}12.4 \% \\
\text { (7.3 to 20.4) }\end{array}$ & $\begin{array}{l}1.53 \\
(0.87 \text { to } 2.70)\end{array}$ & NR & NR \\
\hline
\end{tabular}

${ }^{*}$ Calculated from weighted percentages.

†Weighted percentages.

¥Statistically significant to $\mathrm{P}<0.05$ or less.

$\S$ Calculated from unweighted percentages.

AOR, adjusted OR; NR, not reported; SMW, sexual minority women.

higher rates of obesity, ${ }^{15-1820-22} 2526$ and a recent systematic review on obesity in $\mathrm{SMW}^{36}$ also found consistently higher rates of obesity among SMW compared with heterosexual women. However, the rates of physical exercise in SMW are less clear. Two of the included studies showed higher rates of physical activity or exercise in lesbians and bisexual women compared with heterosexual women, ${ }^{16} 28$ while four showed no differences. ${ }^{2022} 25{ }^{26}$ Hypertension is also associated with mental health difficulties, particularly depression, ${ }^{37}$ and there are higher rates of depression in SMW. ${ }^{34} 35$

No difference in rates of diabetes mellitus was found in the meta-analysis of adjusted ORs, but in the meta-analysis of unadjusted prevalence higher rates were found in bisexual women but not lesbians. It is unclear as to why this would occur. Risk factors for type 2 diabetes mellitus include hypertension, overweight/obesity, physical inactivity and unhealthy diet. Evidence on the first three are discussed above; however, there is much less information available about diet. Dilley et $a l^{19}$ reported that the proportion eating insufficient fruits and vegetables was higher in bisexual women than lesbians and heterosexual women, but Garland-Forshee et $a l^{25}$ showed no differences between lesbians, bisexual and heterosexual women in the proportion who met the US Centers for Disease Control and Prevention (CDC) recommendations on fruit and vegetable intake.
Three of the included studies calculated that lesbians and bisexual women were at higher risk of CVD. ${ }^{18} 2131$ Farmer $e t a l^{21}$ and Clark $e t a l^{31}$ calculated the risk scores using the Framingham General CVD Risk Score and both calculated that SMW had higher CVD risk scores. Farmer et $a l^{21}$ calculated that SMW was $13.9 \% \quad(95 \%$ CI $8.55 \%$ to $19.3 \%$ ) older in vascular terms than their chronological age, and that this was $5.7 \%$ (95\% CI $1.5 \%$ to $9.8 \%$ ) greater than heterosexual women. Clark $e t a \hat{l}^{31}$ found that an average of 30-year CVD risk was raised in all sexual minority groups of women, significantly so in mostly heterosexual and mostly homosexual women. Conron $e t$ $a l^{18}$ also calculated CVD risk using the presence of obesity and smoking plus one other risk factor, including lack of moderate physical activity, lifetime diabetes mellitus, hypertension and high cholesterol. They estimated that lesbians and bisexual women were at higher risk of CVD than heterosexual women.

It is known that there are higher rates of several CVD risk factors in SMW, including overweight/obesity, diabetes mellitus, tobacco use (all discussed above), high cholesterol and harmful use of alcohol (discussed below). Hence the finding of no difference in CVD rates was surprising. Also, since the systematic review found higher rates of asthma, if this was due to higher rates of smoking, it would be expected that there would be correspondingly higher rates of CVD. 


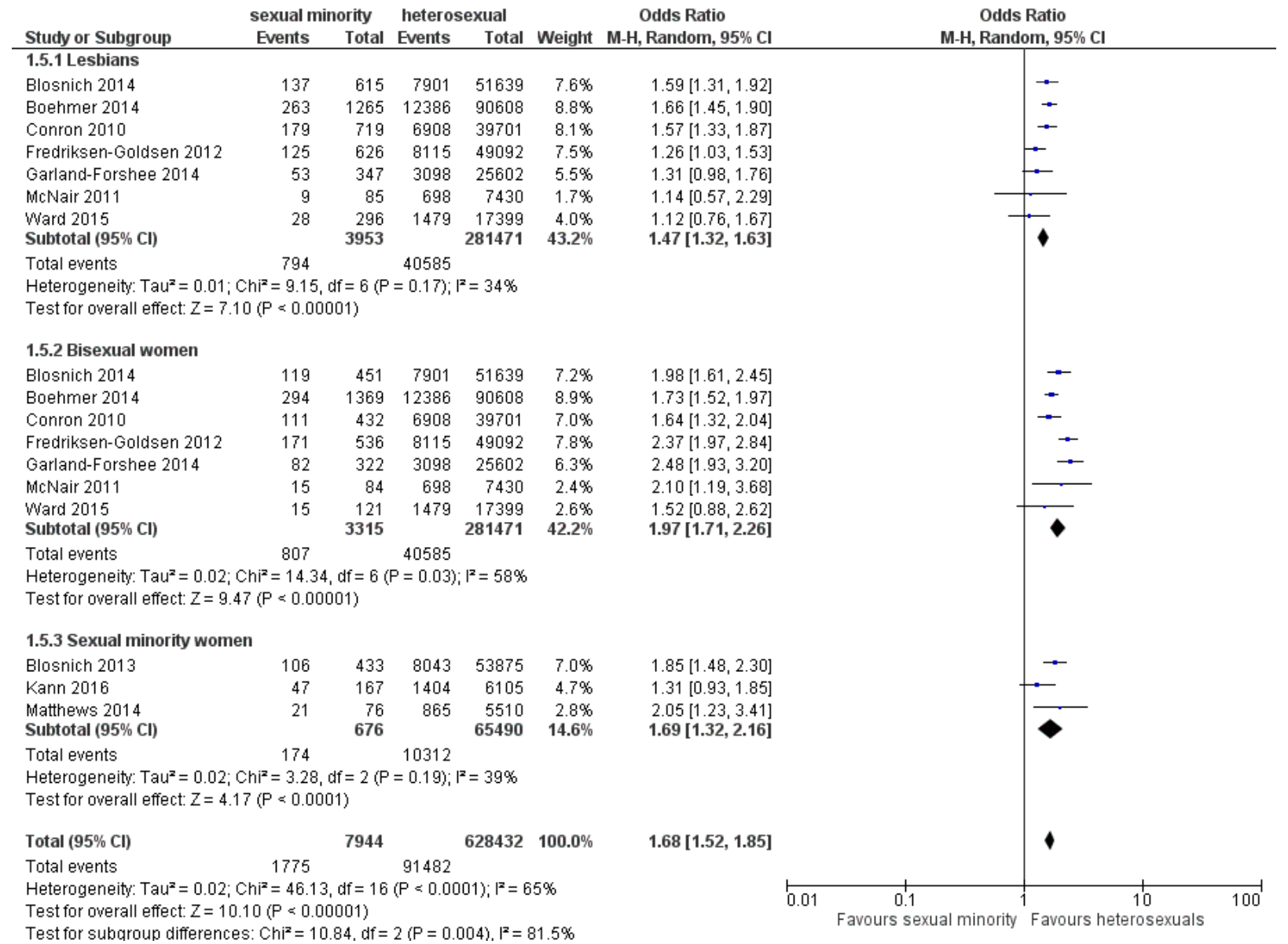

Figure 1 Subgroup meta-analysis of asthma in lesbians, bisexual women and sexual minority women (SMW). M-H, MantelHaenzel.

Several of the included studies reported higher rates of harmful alcohol use in lesbians and bisexual women compared with heterosexuals. ${ }^{16}{ }^{19-21} 232526$ Several also reported cholesterol levels—one found lower cholesterol levels in lesbians and bisexual women, ${ }^{20}$ but most found no significant differences. ${ }^{192325}$ Matthews and Lee ${ }^{28}$ found that twice as many lesbians and bisexual women than heterosexual women were not having their cholesterol checked $(32.5 \%$ vs $13.8 \%)$, but the implications of this are unclear.

\section{Strengths and weaknesses of the study}

The strengths of the current systematic review include extensive searches from a number of different sources; a minor weakness is that the searches were conducted to December 2016 and more studies may have been published since then. We used a wide definition of SMW to include identity, behaviour and partnership. It is acknowledged that these are different concepts and women can identify as lesbian or bisexual without being sexually active or being in a partnership. Also some women identify as lesbian while having sex with men, and some women identify as heterosexual while having sex with women. Most of the studies also used self-report for the physical conditions, and this may result in responder bias, but it is unclear why responder bias might be stronger in SMW than heterosexual respondents. Also, a major limitation is that almost all of the included studies were conducted in the USA, so results may not be generalisable to other countries. Also, it is known that SMW have less insurance coverage and poorer access to healthcare in the USA. ${ }^{38}$ The precise questions on health used in the BRFSS questionnaires asked whether the respondent had been 'told by a health care professional' that they had had the named condition. If SMW have less access to healthcare, it could be assumed that fewer would have been told they had one of the conditions investigated here. So it is possible that all of the rates may have been underestimated, and the increased rates of asthma may be even higher than found here. In the reported results, the prevalence of physical conditions was weighted to better reflect the underlying population in some of the included studies but not in others. Where the sexual minority samples were younger than the heterosexual population with which they were compared, it might be expected that the lack of weighting by age would result in underestimation of the difference in prevalence of physical health conditions, particularly CVD, hypertension and diabetes mellitus, where prevalence rises by age. There were insufficient studies to be able to conduct meaningful subgroup analyses by whether or not the study had controlled for age. Furthermore, two of the studies ${ }^{1623}$ were unclear as to whether they weighted the reported prevalence or whether the reported weighting factors referred to the adjusted ORs that they also report. Some of the studies weighted by factors such as education 
and income, which may also impact on the estimated prevalence of physical conditions. Some important factors were often not controlled for; for example, for asthma, it would be usual to include smoking rates, which differ between SMW and heterosexual female populations.

In the meta-analyses, considerable efforts were made to avoid double-counting of participants from different studies when entering data, and hence some studies were excluded for one or more reported outcomes. ${ }^{19} 233132$ Random-effects models were used because of clinical heterogeneity of the study samples. The heterogeneity between studies in the weightings that were used for the prevalence estimates in the unadjusted meta-analyses may have introduced some bias from this loss of information about differences between the two groups. Hence there may be some inconsistencies between the AORs reported in the results tables and the ORs used in the meta-analysis. The meta-analyses of AORs mitigate some of these effects, and all AORs used were adjusted for age. However, in both types of meta-analyses, there was heterogeneity in outcome measures (eg, one study measured hypertension, six using self-report hypertension and one study using hypertensive medication use), although we do not expect that this impacted on the observed differences between groups, our main outcome of interest.

\section{Strengths and weaknesses in relation to previous research}

The previous systematic reviews ${ }^{12} 13$ found fewer studies and did not conduct meta-analyses so did not quantify the physical health disparities they had found. For CVD prevalence Eliason ${ }^{12}$ included 7 studies, of which 4 were published before 2010, and for hypertension it included 12 studies of which 4 were published before 2010. For asthma it included 13 studies, 4 of which were published before 2010. Some relevant results from included studies were not described, and the study by Garland-Forshee $e t$ $a l^{25}$ was omitted. Eliason ${ }^{12}$ concluded that asthma was more common in SMW, but no differences were consistently found in the other chronic physical conditions she investigated, including diabetes, hypertension and CVD. Simoni $e t$ $a l^{13}$ had a very brief summary of results. For CVD it found one study, for hypertension one study and for asthma four studies. All of these were included in the systematic review by Eliason. ${ }^{12}$ Simoni et $a l^{13}$ found evidence of disparities in the one included study reporting $\mathrm{CVD}^{22}$ and in asthma, but that evidence was lacking in diabetes and hypertension. There is also little information on the prevalence of these conditions in men according to sexual orientation and no relevant systematic reviews. ${ }^{10}$

\section{Implications for clinicians and policy-makers}

If there are higher rates of asthma in lesbians and bisexual women, this might have implications for health service delivery, particularly in primary care. Urwin and Whittaker $^{39}$ published an evaluation of the English General Practice Patient Survey (n=2 807320 in total, 1556909 women) looking at inequalities of general practice (GP) use by sexual orientation for various conditions. They found that lesbians but not bisexual women were less likely to visit the GP than heterosexual women in the previous 3 months for asthma or long-term chest problem (adjusted $\mathrm{OR}=0.84$ ( $95 \%$ CI 0.71 to 0.98 ) and OR=0.85 (95\% CI 0.69 to 1.04 )). So it is likely that SMW, particularly in the UK and possibly elsewhere, are not accessing services despite ill-health. A recent systematic review found that sexual minority populations generally have difficulties with access to health services for a variety of reasons, including communication difficulties, internalised homophobia, prejudicial conduct adopted by health professionals, breach of confidentiality during consultations and institutional homophobia. ${ }^{40}$ Combined with the evidence shown in this systematic review, this suggests potentially considerable latent demand for primary care services among SMW and that there may be particular issues for lesbians accessing primary healthcare services for asthma. This evidence contributes to a bigger picture about inequality for SMW in a wide range of aspects. $^{58}$

This systematic review highlights the need for better routine data collection on SMW, as much of the current research has small sample sizes and is based on one country with different healthcare access and social norms around sexual identity to other countries. The introduction of a UK National Health Service (NHS) information standard on sexual orientation in April $2017^{41}$ will start to introduce routine data capture across hospital episode statistics and disease registries, alongside training across the NHS to support staff having positive conversations about sexual orientation, which will build over time a much clearer picture of the health inequalities in this group and potentially help to reduce them.

\section{Implications for research}

This rigorously conducted systematic review has reported some important new findings on health inequalities in SMW that are hard to explain. Further research would be useful on these health inequalities, including their causes. This would be supported by routine collection of sexual identity measures in population-level epidemiological studies, and the results published. Robust multilevel modelling (including sexual identity) should be conducted with large databases and cohort studies. For asthma, results from large cohort studies, controlled for risk factors such as smoking and overweight/obesity, would be useful to further examine these findings. Regarding hypertension and CVD, the findings are also unexpected, so investigation into potential causes would be very useful, such as possible differences in hormone levels, or other environmental, social, physiological, psychological or genetic factors that might be contributing to these results.

Acknowledgements Professor Richard Riley for advice on conducting metaanalyses of adjusted ORs, and Dr Brendon Stubbs for conducting the meta-analyses of adjusted ORs.

Contributors JV and CM developed the research question. CM and AM conducted the systematic review (searches, citation selection, data extraction, quality assessment). CM wrote the systematic review, and all data were checked by AM and JG. CM conducted the meta-analysis, checked by AM. All authors edited the manuscript. 
Funding Public Health England grant ( $£ 30000)$ to RAND Europe for writing the full WSW best evidence review. The funder did not influence the conduct of the review.

Competing interests None declared.

Patient consent Not required

Provenance and peer review Not commissioned; externally peer reviewed.

Data sharing statement There are no unpublished data as this is a systematic review.

Open Access This is an Open Access article distributed in accordance with the Creative Commons Attribution Non Commercial (CC BY-NC 4.0) license, which permits others to distribute, remix, adapt, build upon this work non-commercially, and license their derivative works on different terms, provided the original work is properly cited and the use is non-commercial. See: http://creativecommons.org/ licenses/by-nc/4.0/

(C) Article author(s) (or their employer(s) unless otherwise stated in the text of the article) 2018. All rights reserved. No commercial use is permitted unless otherwise expressly granted.

\section{REFERENCES}

1. Public Health England. Producing modelled estimates of the size of the lesbian, gay and bisexual (LGB) population of England. 2016 https://www.gov.uk/government/uploads/system/uploads/ attachment_data/file/585349/PHE_Final_report_FINAL_DRAFT_14. 12.2016NB230117v2.pdf

2. Newton JN, Briggs AD, Murray CJ, et al. Changes in health in England, with analysis by English regions and areas of deprivation, 1990-2013: a systematic analysis for the Global Burden of Disease Study 2013. Lancet 2015;386:2257-74.

3. Bhattacharya R, Shen $\mathrm{C}$, Sambamoorthi U. Excess risk of chronic physical conditions associated with depression and anxiety. BMC Psychiatry 2014;14:10.

4. Clarke DM, Currie KC. Depression, anxiety and their relationship with chronic diseases: a review of the epidemiology, risk and treatment evidence. Med J Aust 2009;190:S54-S60.

5. Committee on lesbian, gay, bisexual and transgender health issues and research gaps and opportunities. The health of lesbian, gay, bisexual and transgender (LGBT) people: building a foundation for better understanding. Washington DC: Board on the Health of Select Populations; Institute of Medicine, The National Academy of Science, 2011.

6. Coulter RW, Kenst KS, Bowen DJ, et al. Research funded by the National Institutes of Health on the health of lesbian, gay, bisexual, and transgender populations. Am J Public Health 2014;104:e105-12.

7. Meads C, Pennant M, McManus J, et al. A systematic review of lesbian, gay, bisexual and transgender health in the West Midlands region of the UK compared to published UK research. Birmingham: University of Birmingham, 2009. http://www.birmingham.ac.uk/ Documents/collegemds/haps/projects/WMHTAC/REPreports/2009/L GBThealth030409finalversion.pdf

8. Hudson-Sharp N, Metcalf H. Inequality among lesbian, gay bisexual and transgender groups in the UK: a review of evidence. London: National Institute of Economic and Social Research, 2016.

9. Edmondson D, Hodges R, Williams H. The lesbian, gay, bisexual and trans public health outcomes framework companion document, 2016 update: National LGB\&T Partnership, 2016.

10. Blondeel K, Say L, Chou D, et al. Evidence and knowledge gaps on the disease burden in sexual and gender minorities: a review of systematic reviews. Int J Equity Health 2016;15:16.

11. Wang $\mathrm{H}$, Naghavi $\mathrm{M}$, Allen $\mathrm{C}$, et al. Global, regional, and national life expectancy, all-cause mortality, and cause-specific mortality for 249 causes of death, 1980-2015: a systematic analysis for the Global Burden of Disease Study 2015. Lancet 2016;388:1459-544.

12. Eliason MJ. Chronic physical health problems in sexual minority women: review of the literature. LGBT Health 2014;1:259-68.

13. Simoni JM, Smith L, Oost KM, et al. Disparities in physical health conditions among lesbian and bisexual women: a systematic review of population-based studies. J Homosex 2017;64.

14. Higgins G, Green S. Cochrane handbook of systematic reviews of interventions. Chichester: Wiley-Blackwell, 2008.

15. Blosnich JR, Lee JG, Bossarte R, et al. Asthma disparities and within-group differences in a national, probability sample of samesex partnered adults. Am J Public Health 2013;103:e83-7.

16. Blosnich JR, Farmer GW, Lee JG, et al. Health inequalities among sexual minority adults: evidence from ten U.S. states, 2010. Am J Prev Med 2014;46:337-49.
17. Boehmer U, Miao X, Linkletter $\mathrm{C}$, et al. Health conditions in younger, middle, and older ages: are there differences by sexual orientation? LGBT Health 2014;1:168-76.

18. Conron KJ, Mimiaga MJ, Landers SJ. A population-based study of sexual orientation identity and gender differences in adult health. Am J Public Health 2010;100:1953-60.

19. Dilley JA, Simmons KW, Boysun MJ, et al. Demonstrating the importance and feasibility of including sexual orientation in public health surveys: health disparities in the Pacific Northwest. Am J Public Health 2010;100:460-7.

20. Everett B, Mollborn S. Differences in hypertension by sexual orientation among U.S. young adults. J Community Health 2013;38:588-96.

21. Farmer GW, Jabson JM, Bucholz KK, et al. A population-based study of cardiovascular disease risk in sexual-minority women. Am J Public Health 2013;103:1845-50.

22. Fredriksen-Goldsen KI, Kim HJ, Barkan SE, et al. Disability among lesbian, gay, and bisexual adults: disparities in prevalence and risk. Am J Public Health 2012;102:e16-e21.

23. Fredriksen-Goldsen $\mathrm{KI}$, Kim HJ, Barkan SE, et al. Health disparities among lesbian, gay, and bisexual older adults: results from a population-based study. Am J Public Health 2013;103:1802-9.

24. Frisch M, Simonsen J. Marriage, cohabitation and mortality in Denmark: national cohort study of 6.5 million persons followed for up to three decades (1982-2011). Int J Epidemiol 2013;42:559-78.

25. Garland-Forshee RY, Fiala SC, Ngo DL, et al. Sexual orientation and sex differences in adult chronic conditions, health risk factors, and protective health practices, Oregon, 2005-2008. Prev Chronic Dis 2014;11:140126.

26. Jackson CL, Agénor M, Johnson DA, et al. Sexual orientation identity disparities in health behaviors, outcomes, and services use among men and women in the United States: a cross-sectional study. BMC Public Health 2016;16:807.

27. Kann L, Olsen EO, McManus T, et al. Sexual identity, sex of sexual contacts, and health-related behaviors among students in grades 9-12 - United States and Selected Sites, 2015. MMWR Surveill Summ 2016;65:1-202.

28. Matthews DD, Lee JG. A profile of North Carolina lesbian, gay, and bisexual health disparities, 2011. Am J Public Health 2014;104:e98-e105.

29. McNair RP, Hegarty K. Guidelines for the primary care of lesbian, gay, and bisexual people: a systematic review. Ann Fam Med 2010;8:533-41.

30. Ward BW, Joestl SS, Galinsky AM, et al. Selected diagnosed chronic conditions by sexual orientation: a national study of US adults, 2013. Prev Chronic Dis 2015;12:150292.

31. Clark CJ, Borowsky IW, Salisbury J, et al. Disparities in long-term cardiovascular disease risk by sexual identity: the national longitudinal study of adolescent to adult health. Prev Med 2015;76:26-30.

32. Wallace SP, Cochran SD, Durazo EM, et al. The health of aging lesbian, gay and bisexual adults in California. Los Angeles: UCLA Center for Health Policy Research, 2011.

33. Thomas M, Bruton A, Moffat M, et al. Asthma and psychological dysfunction. Prim Care Respir J 2011;20:250-6.

34. Semlyen J, King M, Varney J, et al. Sexual orientation and symptoms of common mental disorder or low wellbeing: combined meta-analysis of 12 UK population health surveys. BMC Psychiatry 2016;16:67.

35. King M, Semlyen J, Tai SS, et al. A systematic review of mental disorder, suicide, and deliberate self harm in lesbian, gay and bisexual people. BMC Psychiatry 2008;8:70.

36. Eliason MJ, Ingraham N, Fogel SC, et al. A systematic review of the literature on weight in sexual minority women. Womens Health Issues 2015;25:162-75

37. Meng L, Chen D, Yang Y, et al. Depression increases the risk of hypertension incidence: a meta-analysis of prospective cohort studies. J Hypertens 2012;30:842-51.

38. Dahlhamer JM, Galinsky AM, Joestl SS, et al. Barriers to health care among adults identifying as sexual minorities: a US National Study. Am J Public Health 2016;106:1116-22.

39. Urwin $\mathrm{S}$, Whittaker W. Inequalities in family practitioner use by sexual orientation: evidence from the English General Practice Patient Survey. BMJ Open 2016;6:e011633.

40. Alencar Albuquerque G, de Lima Garcia C, da Silva Quirino G, et al. Access to health services by lesbian, gay, bisexual, and transgender persons: systematic literature review. BMC Int Health Hum Rights 2016;16:2.

41. Standardisation Committee for Care Information (SCCl). Advance notification-new information standard. http://content.digital.nhs.uk/ media/22530/2094512015an/pdf/2094512015an.pdf (accessed Mar 2017). 